\title{
FUNDAMENTOS ÉTICOS PARA LA PROMOCIÓN DE LA AUTONOMÍA: HACIA UNA ÉTICA DE LA INTERDEPENDENCIA
}

\section{Ethical grounds for promoting autonomy: towards an ethic of interdependence}

\author{
FRANCISCO GUZMÁN CASTILLO* \\ MARIO TOBOSO MARTÍN** \\ JAVIER ROMAÑACH CABRERO***
}

\section{Resumen}

Las políticas sociales se fundamentan en modelos éticos, antiguos y nuevos, que se implantan paulatinamente en la sociedad. Los modelos tradicionales, además de basarse en las éticas kantianas o deontológicas y consecuencialistas, incluyen otras aportaciones, entre las que podemos reseñar las de Hans Jonas, Martha Nussbaum o Alasdair MacIntyre. Sin embargo, sólo se producen innovaciones importantes cuando un colectivo «no tradicional» hace su voz presente en el mundo de la ética. Actualmente el modelo social y el modelo de la diversidad aportan una nueva voz, que nace de las

* Francisco Guzmán Castillo

Instituto de Filosofía, Centro de Ciencias Humanas y Sociales, CSIC

C/ Albasanz, 26-28. 28037 Madrid

Teléfono: 916022300 Fax: 916022971

paco.guzman@cchs.csic.es

* Mario Toboso Martín

Instituto de Filosofía, Centro de Ciencias Humanas y Sociales, CSIC

C/ Albasanz, 26-28. 28037 Madrid

Teléfono: 916022300 Fax: 916022971

mario.toboso@cchs.csic.es

*** Javier Romañach Cabrero

Foro de Vida Independiente

C/ Raimundo Fernández Villaverde, 53, 9d. 28003 Madrid

Teléfono: 9153477 59/670 216894

jromanac@diversocracia.org 
personas discriminadas por su diversidad funcional y que tiene fuertes implicaciones en los fundamentos éticos de las políticas sociales. En este texto se abordan las novedades y críticas que esta nueva voz aporta a la ética contemporánea, con especial énfasis en la presencia o ausencia de la misma en la Ley de Promoción de la Autonomía Personal y Atención a las personas en situación de dependencia.

Palabras clave: ética de la interdependencia, ética del cuidado, ley de dependencia, diversidad funcional, modelo social, modelo de la diversidad.

\begin{abstract}
Social policy is based on both old and new ethical models that are introduced gradually into society. Traditional models are not only based on Kantian, deontological and consequentialist ethics, they also include contributions such as those by Hans Jonas, Martha Nussbaum and Alasdair MacIntyre. However, important innovations only occur when a «non-traditional» collective makes its voice heard in the world of ethics. This new voice is currently being provided by social and diversity models, and which stems from people being discriminated against due to their functional diversity, with major implications in the ethical grounding of social policy. This text considers what this new voice brings to contemporary ethics and how it is considered, with particular emphasis on the presence or absence of this voice in the Personal Autonomy and Dependent Care Law.
\end{abstract}

Keywords: ethics of interdependence, ethics of care, Dependent Care Law, functional diversity, social model, diversity model.

\title{
1. Teorías éticas clásicas
}

Hasta un momento muy reciente, el destinatario de las teorías éticas ha venido siendo un ser humano dotado de unas competencias básicas indispensables para ejercer la acción moral: la racionalidad, el carácter y el juicio en Aristóteles; la caridad, la misericordia y la beneficencia en la ética cristiano-medieval; el sentimiento de benevolencia y cierta capacidad física y mental para oponerse a una posible dominación en Hume, la autonomía moral basada en la razón en Kant, etc., todas ellas aptitudes básicas para ser considerado sujeto moral agente, es decir, aquel que actúa bien sobre otro. ${ }^{1}$

En cuanto al sujeto moral paciente, que recibe la acción del agente, sólo es incluido como miembro de pleno derecho en este intercambio ético si reúne las competencias exigidas a los agentes morales. Al carecer de alguna de estas competencias se puede ser objeto de la acción moral, pero puesto que desde un punto de vista ético-antropológico no se disfruta del mismo estatus que el

1. Véanse, por ejemplo: Aristóteles, Ética a Nicómaco, Retórica; Tomás de Aquino, Suma Teológica; Hume, Investigación sobre los principios de la moral, Tratado de la naturaleza humana; Kant, Fundamentación de la metafísica de las costumbres, Metafísica de las costumbres. 
sujeto moral agente, la relación de intercambio será asimétrica, favoreciendo comportamientos opresivos y consideraciones prejuiciosas y discriminatorias.

Los tratados de ética y filosofía se aproximan a la realidad de las personas con diversidad funcional ${ }^{2}$ a través del análisis de la inherente fragilidad del ser humano desde dos supuestos diferentes. En primer lugar se considera al ser humano frágil como un objeto de la acción ética del sujeto, alguien a quien se sitúa en un plano inferior de existencia y al que se trata de ayudar para que recupere su estatus de ser humano autónomo, autosuficiente, sano, etc. Desde este punto de vista se estudia el mejor modo de tratar a quienes padecen penalidades y las maneras de fomentar medios morales y sociales para su superación o erradicación. Todas las éticas anteriores al siglo XX (como la aristotélica, la cristiana y las de Hume y Kant, entre otras) se encuadran en este tipo y sitúan a la persona con diversidad funcional en la categoría de «objeto» sobre el que se actúa moralmente. Aunque contengan algunas ideas que se pueden rescatar para una ética de la interdependencia, todas ellas limitan sus potenciales emancipatorios al grupo de los competentes según su particular visión, apropiándose de la voz de los excluidos. En segundo lugar se considera al ser humano dependiente como un «sujeto» de la acción ética sobre otros seres humanos dependientes por otras o las mismas razones. Desde este punto de vista se critica cualquier sistema social o de conocimiento que fomente la distinción entre los necesitados y los autosuficientes, de manera que los medios sociales se orientan a desarticular esta desigualdad de partida, distribuyéndose de modo tal que contribuyan a eliminar cualquier diferencia de estatus derivada de un diseño social discriminatorio (Sutherland, 1981; Zola, 1989; MacIntyre, 2001).

\section{Contractualismo del siglo XX}

El contractualismo, que tiene sus raíces en Rousseau y Kant, establece que la sociedad es una empresa cooperativa, fruto del acuerdo o contrato entre iguales, para obtener ventajas comunes. Las teorías contractualistas clásicas se basan, generalmente, en una visión pesimista de la naturaleza humana, que se compensa gracias a un orden natural optimista que finalmente siempre se impone. Pero, ¿quiénes son los beneficiarios de este orden de bien y justicia fruto del miedo, el egoísmo y la desconfianza mutua? Precisamente quienes provocan estos mismos sentimientos.

2. Acerca de la propuesta del término «diversidad funcional» como revisión crítica del concepto de «discapacidad», véase Romañach y Lobato (2005). A lo largo del artículo asumimos esta propuesta. 
Los autores contemporáneos del contractualismo se preocupan por el proceso a través del cual se elabora el contrato de convivencia justa entre individuos o grupos con necesidades e intereses distintos. En este terreno hay dos cuestiones que afectan especialmente a las personas con diversidad funcional. La primera, definir quiénes son los sujetos que determinan cuáles van a ser los principios de justicia que regirán en la sociedad. Esto, en la teoría de Rawls (1995), se decide en la posición original que está ocupada por aquellos que tienen reconocida una mínima personalidad moral y una plena capacidad de cooperación social. Si alguien no cumple con este mínimo establecido por la teoría, no puede participar plenamente y se convierte en un sujeto pasivo del juego de la convivencia. Esto les ocurre a las personas con diversidad funcional, que se sienten discriminadas porque viven en una sociedad que ha sido diseñada sin tener en cuenta su voz.

Rawls, en su Teoría de la Justicia, reconoce sus dudas sobre una posible extensión de su concepto de la justicia social hacia las personas con diversidad funcional, que por no ser plenamente cooperantes no pueden satisfacer las condiciones mínimas de participación social igualitaria. Únicamente señala que desde sus principios de justicia pueden establecerse criterios para fomentar un servicio normal de salud (Rawls, 1995: 51); una actitud clásica (entre lo despótico y lo paternalista) con la cual se regresa al modelo médico de la discapacidad, en lugar de avanzar hacia nuevas propuestas éticas. ${ }^{3}$

En una línea diferente, Amartya Sen desarrolla su «enfoque de las capacidades» intentando ampliar y modificar los planteamientos de Rawls, en el ámbito de la economía, como una evaluación comparativa de la calidad de vida en diferentes sociedades (Sen, 1985, 1993, 1999). El concepto de «capacidad» de Sen consiste en un conjunto de seres y quehaceres valiosos a los que el individuo puede acceder libremente gracias a que vive en sociedad. El concepto de «funcionamiento» refleja esas diversas cosas que una persona puede valorar ser o hacer. Los funcionamientos valorados pueden ir desde los más elementales: estar alimentado, no padecer enfermedades evitables, la higiene, el descanso, etc., hasta otros más complejos, como participar en la vida comunal, disfrutar del ocio, de la sexualidad, viajar, formar una familia (Cejudo, 2007); todo aquello relacionado con el respeto a uno mismo y a su propio concepto de vida digna. ${ }^{4}$

3. Modelo que reduce la diversidad funcional a los aspectos biomédicos del ser humano y que ha sido ya descartado legalmente por la Convención Internacional de la ONU sobre los Derechos de las Personas con Discapacidad (diversidad funcional).

4. Los funcionamientos más complejos suelen ser guías de las preferencias y valoración que sobre los elementales tienen las personas, pero no se les suele considerar a la hora 
La labor de una sociedad justa es producir y mantener activos estos funcionamientos (Toboso y Arnau, 2008), para que la mayor diversidad posible de personas acceda a los mismos con el fin de alcanzar sus fines, y así habrá disponibles más funcionamientos para que otros los utilicen como capacidad. ${ }^{5}$

La segunda cuestión en la que el contractualismo incide en la diversidad funcional remite al análisis de qué derechos o recursos básicos debe garantizar la sociedad a los individuos para llevar a cabo su proyecto de vida. Martha Nussbaum (2007) presenta su propia versión del «enfoque de las capacidades» como una revisión mejorada del contractualismo rawlsiano, que incluye el reconocimiento del deber moral hacia aquellos miembros que puedan ser considerados no plenamente cooperantes, más allá del mero beneficio mutuo como motivo para acordar los principios de convivencia. Su noción de la persona, de raíz aristotélica, la define como una criatura social y política necesitada de una pluralidad de actividades vitales, a las que se accede a través de una serie de capacidades esenciales que la sociedad debe garantizar. Sin embargo, aunque su modelo es más solidario que el del contractualismo anterior, impone la solidaridad forzosa de un concepto de la vida buena determinado por la experiencia cultural de quien define la lista de capacidades (Nussbaum, 2007).

\section{Nuevos paradigmas éticos}

También resultan aplicables a este ámbito otras voces de filósofos contemporáneos cuyas aportaciones se salen de lo analizado anteriormente. Entre ellos podemos destacar a Hans Jonas y Alasdair MacIntyre.

En la perspectiva de Jonas, el arquetipo de la responsabilidad, que es el deber de los padres de cuidar a los hijos, se establece a partir de una relación asimétrica y no recíproca (Jonas, 1995). El ser necesitado de cuidado lleva consigo de un modo inmanente y evidente un «deber» para otros que han de atender a su cuidado. Así, recuperando el finalismo aristotélico, considera que el ser, en cuanto fin en sí mismo, está dotado ya de un valor intrínseco (Becchi, 2008: 120). Esto es importante señalarlo porque parecería que, desde esta argumentación, el ser frágil tiene como fin natural convocar en los demás

de diseñar políticas sociales. Por ejemplo, en las políticas sociales de atención a la diversidad funcional se da mayor importancia a las necesidades médicas y a la realización de actividades básicas de la vida diaria, como el aseo o la alimentación, mientras que actividades como el disfrute del ocio o de los viajes no se tienen en cuenta.

5. Esta es una de las razones por las que creemos que es interesante no excluir la diversidad funcional de la sociedad, porque abre el espacio de posibilidades a nuevas formas de estar en el mundo que pueden ser aprovechadas por todos. 
el deber moral de ser ayudado, sin reconocer, en principio, mayor alcance en su existencia, cayendo de esta manera en el mismo error que la ética cristiana, que redujo al ser frágil a objeto de caridad.

La dimensión no recíproca de la responsabilidad es clave a la hora de aplicar el paralelismo que Jonas establece entre la responsabilidad paterno filial y la responsabilidad del Estado y las instituciones sociales para que posibiliten que los ciudadanos, sobre todo aquellos que se encuentren en situación de dependencia, puedan recibir la atención que requieran para ser felices. La responsabilidad recíproca establecida entre, digamos, iguales (por ejemplo, empresas colectivas, hermanos, amigos), siendo necesaria y sólida, es sin embargo menos incondicional que la responsabilidad asimétrica, tal y como la experimentan, de modo paradigmático, los padres respecto al cuidado de los hijos (Bonete, 2009: 51). Para formarnos una opinión de la bondad del Estado social, habría que dar importancia a las oportunidades de que disfrutan las diferentes personas para alcanzar el propio bienestar, como reflejo de qué cartas ha repartido la sociedad a cada una de ellas.

Vemos, pues, que Jonas nos provee de la justificación última en la que fundar nuevos desarrollos sociales con nuevos valores éticos, ya que para él es natural este tipo de avances en la sociedad. Pese a ello, aunque señala que el supremo cumplimiento de la responsabilidad es la abdicación, la autonomía y la voz del paciente que recibe la acción moral del sujeto responsable no parece tenerse muy en cuenta a lo largo del proceso.

Por su parte, Alasdair MacIntyre, plantea la conveniencia de repensar la ética a partir de la constatación de que somos seres débiles y que, por tanto, dependemos constantemente los unos de los otros para vivir humanamente. El núcleo de la condición humana no ha sido realmente analizado en sus implicaciones éticas (MacIntyre, 2001: 15): «Los seres humanos son vulnerables a una gran cantidad de aflicciones diversas y la mayoría padece alguna enfermedad grave en uno y otro momento de su vida. La forma como cada uno se enfrenta a ello depende sólo en una pequeña parte de sí mismo. Lo más frecuente es que todo individuo dependa de los demás para su supervivencia, no digamos ya para su florecimiento, cuando se enfrenta a una enfermedad o lesión corporal, una alimentación defectuosa, deficiencias y perturbaciones mentales y la agresión o negligencia humanas. Esta dependencia de otros individuos a fin de obtener protección y sustento resulta muy evidente durante la infancia y la senectud, pero entre estas primera y última etapas en la vida del ser humano suele haber periodos más o menos largos en que se padece alguna lesión, enfermedad o discapacidad, y hay algunos casos en que se está discapacitado de por vida». 
Uno de los motivos que, según MacIntyre, impulsa a cuidar de la persona dependiente es la constatación de que uno mismo podría ser quien padece alguna inesperada enfermedad o accidente paralizante. Este autor sostiene que una comunidad se desarrolla en la medida en que la necesidad urgente de alguno de sus miembros es la que provee razones suficientes para que otros reaccionen de un modo moral ante sus padecimientos, sin recurrir a argumentos sutiles o filosóficos para impulsar la acción (Bonete, 2009: 79). El planteamiento de MacIntyre apunta directamente a la dimensión social y política del problema de la fragilidad y la dependencia humanas. Su intención es imaginar una sociedad política que, según sus propias palabras, «parte del hecho de que la discapacidad y la dependencia es algo que todos los individuos experimentan en algún momento de su vida y de manera impredecible, por lo que el interés de que las necesidades que padecen las personas discapacitadas sean adecuadamente expresadas y atendidas no es un interés particular de un grupo de individuos concretos, sino que es el interés de la sociedad política entera y esencial en su concepto del bien común» (MacIntyre, 2001: 154).

Tanto las revisiones del contractualismo clásico de Nussbaum y Sen, como los nuevos paradigmas éticos de Jonas y MacIntyre plantean la inevitable necesidad de afrontar el tema de la fragilidad y la dependencia humana en el mundo de la filosofía ética y política. No obstante, para profundizar en los nuevos valores éticos, nos parecen más interesantes las éticas surgidas de las voces nunca escuchadas y que hablan en primera persona.

\section{Nuevas voces éticas en primera persona: ética del cuidado o de la implicación}

En 1977, Carol Gilligan, psicóloga feminista estadounidense, escribía el influyente artículo: «In a Different Voice: Women's Conceptions of Self and of Morality», y en 1982 el libro In a different voice: psychological theory and women's development, en el que a través de varios casos concretos desvela la diferente aproximación a la filosofía moral que tienen los hombres y las mujeres. Siguiendo a la autora Soledad Arnau (2009): «[... Gilligan, establece una distinción que considera irrevocable. Debido fundamentalmente a los roles tradicionales de género, se establecen dos tipologías de ética: ética de la justicia, de carácter predominantemente de género masculino; y la ética del cuidado (o también, "ética de la responsabilidad"), proveniente del género femenino».

La ética del cuidado surgió, pues, a partir del trabajo de Carol Gilligan en los años ochenta, que dio importancia, desde la perspectiva del feminismo, a la manera en que las mujeres parecían abordar los problemas éticos, es decir, a través de prácticas relacionadas con el cuidado. Sin embargo, la palabra 
«cuidado» en español no abarca todos los aspectos contenidos en la noción anglosajona de care. Nel Noddings desarrolla el concepto indicando que: «Preocuparse por otra persona, en su aspecto más significativo, es ayudarle a crecer y a adaptarse» (Noddings, 1984: 9) y que «cuando nos preocupamos, consideramos el punto de vista de la otra persona y qué es lo que espera de nosotros. Nuestra atención, nuestra ocupación mental está en aquel del que nos ocupamos, no en nosotros. Nuestras razones de actuar tienen que ver con lo que la otra persona quiere ser y con los elementos objetivos de su situación problemática» (Noddings, 1984: 24). Visto lo anterior, creemos que estos aspectos de la ética quedan mejor reflejados en palabras como «implicación»o «preocupación», ya que la palabra cuidado no siempre revela una atención hacia el punto de vista del sujeto cuidado.

Esta perspectiva aporta una manera más humana y menos abstracta de establecer valores que guíen la acción ética, donde las relaciones parecen menos asimétricas, y aparece de manera natural la noción de «interdependencia», ya que establece que aquel por el que nos preocupamos (cared-for) depende del que se preocupa (one-caring), tanto como éste de aquél (Noddings, 1984: 48). Esto sienta las bases de una relación menos asimétrica que la de la relación del cuidado a la dependencia. Gracias a la ética de la implicación, pasamos a una situación de interdependencia en la que es posible una nueva construcción ética y social (Marín, 1993).

La ética de la «implicación» es una voz nueva y distinta, pero hay que tener presente que en sus premisas y reflexiones nunca tuvo en cuenta a la diversidad funcional, ni a las mujeres discriminadas por su diversidad funcional (Arnau, 2009).

\subsection{El modelo social de la «discapacidad»}

Lo que hoy se conoce como el modelo social de la «discapacidad $»^{6}$ tiene sus orígenes en el Movimiento de Vida Independiente ${ }^{7}$ de lucha por los derechos civiles de las personas con diversidad funcional, que tuvo lugar en Estados Unidos a partir de los años sesenta, en el que se establecieron importantes cambios de paradigma para aproximarse a esta realidad humana desde el punto de vista ético. El principal cambio consistió en que este modelo dio voz por primera vez, a las personas con diversidad funcional, como auténticas protagonistas de la deliberación pública de las prácticas y políticas sociales que les

6. Acerca de los dos modelos aquí resumidos, véase Palacios (2008).

7. Para profundizar en la historia del movimiento de Vida Independiente, véanse García Alonso (2003) y Maraña (2004, 2007). 
afectaban directamente. Esto fue así en buena medida gracias a que los inventores y promotores de este modelo eran personas con diversidad funcional.

Este conjunto de ideas llegó a Europa a través de Gran Bretaña y los países nórdicos y fue en este primer país donde que sus ideas fueron tamizadas para adaptarlas a la realidad europea; una realidad mucho más social que la sociedad liberal estadounidense (Palacios, 2008: 106). El modelo de Vida Independiente pasó a ser denominado modelo social, y es así como ha sido internacionalizado. En este proceso, el modelo se tornó más académico y en su desarrollo tuvo un fuerte impacto la sociología académica británica, que llegó a establecer estudios específicos sobre la diversidad funcional en universidades como la de Leeds, en donde han destacado sociólogos como Colin Barnes, Len Barton, Tom Shakespeare, etc ${ }^{8}$.

El modelo social asume la premisa de que la discapacidad es una construcción y un modo de opresión social. Asimismo, reivindica la autonomía de la persona con diversidad funcional para decidir respecto de su propia vida, y para ello se centra en la eliminación de cualquier tipo de barrera, con el fin de brindar una adecuada igualdad de oportunidades. Estas barreras incluyen inaccesibilidad en la educación, en los sistemas de comunicación e información, en los entornos de trabajo, sistemas de beneficencia inadecuados para las personas con discapacidad, servicios de apoyo social y sanitarios discriminatorios, transporte, viviendas y edificios públicos y de entretenimiento inaccesibles y la devaluación de las personas etiquetadas como discapacitadas por la imagen y su representación negativa en los medios de comunicación, películas, televisión y periódicos. Desde esta perspectiva, las personas con discapacidad son discapacitadas como consecuencia de la negación por parte de la sociedad de acomodar las necesidades individuales y colectivas dentro de la actividad general que supone la vida económica, social y cultural. (Barnes, 2000, citado en Palacios, 2008: 121).

Como podemos observar, el modelo social se alinea con el objetivo de este texto, ya que arranca del planteamiento de la interdependencia y de la gradualidad de las situaciones de «inDependencia» (Arnau, 2008).

\subsection{El modelo de la diversidad}

El modelo social tardó más de 20 años en llegar a una España en la que la mayor parte de las cuatro mil asociaciones del sector permanecían ancladas en el modelo médico, al igual que ocurre en el ámbito académico. La introducción

8. Véanse, por ejemplo, Oliver (1990), Shakespeare (1993, 1994), Barnes y Mercer (1996), Barnes $(1998,2000)$ y Barnes, Oliver y Barton (2002). 
de este modelo en nuestra sociedad fue impulsada por el Foro de Vida Independiente $(\mathrm{FVI})^{9}$, una comunidad virtual de información y discusión, creada en el 2001 por un grupo muy reducido de personas y que ahora cuenta con más de 800 miembros.

Aunque desde el punto de vista político las propuestas del modelo social parecen suficientes para conseguir legalmente la igualdad de oportunidades y la ausencia de discriminación, desde el ámbito de la ética, algunos autores, miembros del Foro, han comenzado a señalar que este modelo tiene carencias. Así, Agustina Palacios (2008: 141) señala que «toda vida humana, con independencia de la naturaleza o complejidad de la diversidad funcional que le afecte, goza de igual valor en dignidad. Debe destacarse, sin embargo, que esta afirmación resulta muy difícil de ser llevada a la práctica, dado que la misma fundamentación de la idea de dignidad humana actual parte desde un modelo de ser humano capaz. Es por ello que quizás se requiera una nueva definición de la idea de dignidad que no deje a nadie afuera, ni dé lugar a interpretaciones que supongan que determinados seres humanos pueden ser más dignos que otros». Además plantea que «Las personas con discapacidad tienen el derecho a la igualdad de oportunidades, en razón de su igual humanidad, y no por ser iguales funcionalmente. De otro modo, el contenido central del imperativo categórico kantiano estaría siendo vulnerado, ya que si valoramos a la persona en la medida de su aporte a la comunidad, estaremos considerando al ser humano como un medio y no como un fin en sí mismo» (Palacios, 2008: 164). Con estos argumentos se cuestiona la noción tradicional de dignidad humana manejada por el modelo social, basado en la capacidad de una serie de competencias, generalmente racionales, consideradas propias del ser humano funcional.

Bajo estos planteamientos nació el denominado «modelo de la diversidad», planteado en 2006 por Agustina Palacios y Javier Romañach en el libro El modelo de la diversidad: La Bioética y los Derechos Humanos como herramientas para alcanzar la plena dignidad en la diversidad funcional. El modelo fue presentado por sus autores como una extensión del modelo social, que ofrece tres propuestas: en primer lugar, el uso del término diversidad funcional (que se ha venido utilizando en este artículo) en sustitución del término discapacidad como expresión positiva de esta situación vital que es inherente a la vida humana. En segundo lugar, la aceptación de la diversidad funcional planteada como una más de las diversidades que conforman y enriquecen la humanidad (género, raza, orientación sexual, religión, nacionalidad, etc.). Y, por último,

9. Véase <http://www.forovidaindependiente.org> 
el reconocimiento de la plena dignidad en la diversidad funcional, para lo cual se establecen dos ideas o valores fundamentales: dar el mismo valor a las vidas de todos los seres humanos, sea cual sea su diversidad funcional, y garantizar los mismos derechos y oportunidades a todas las personas.

Palacios y Romañach, conscientes de la incoherente aproximación del modelo social a la dignidad, basada en las nociones tradicionales de autonomía y capacidad, decidieron utilizar un concepto «instrumental» de la dignidad. Para ello se basaron en el análisis de la aparición de dicho término en textos legales nacionales, textos bioéticos y textos de declaraciones internacionales aprobados por la inmensa mayoría de los estados (Romañach y Palacios, 2006: 135-174).

Por otro lado, el modelo apunta las potenciales consecuencias para la sociedad, en función de que decida utilizar o no dichos valores «universales». Partiendo de experiencias previas en las que la plena dignidad humana no fue respetada, con consecuencias sociales y humanas desastrosas, como fueron Esparta o la Alemania nazi, el modelo propone la aceptación de sus valores como fundamentos imprescindibles para la construcción de una sociedad justa y libre (Romañach y Palacios, 2006: 222-223): «El modelo de la diversidad propone claves para construir una sociedad en la que todas las mujeres y hombres vean preservada plenamente su dignidad. Una sociedad en la que la diversidad, y en concreto la diversidad funcional, sea vista como una diferencia con valor y no como una carga independientemente de la edad a la que se produzca. Una sociedad en la que exista la igualdad de oportunidades y nadie sea discriminado por su diferencia. En definitiva, una sociedad más justa en la que todas las personas sean bienvenidas, aceptadas y respetadas por el simple hecho de ser humanos».

\section{Reflejo en el derecho}

Las teorías éticas analizadas en este trabajo tienen su reflejo en las diferentes leyes que sucesivamente se implantan para tratar el fenómeno de la diversidad funcional (discapacidad). Es por ello que los fundamentos analizados en este artículo, referentes a la ética de la interdependencia y de la promoción de autonomía, quedarían en meras opiniones o ideas si no acabasen reflejados en los textos legales.

En la legislación española se da con frecuencia un caso de incoherencia plena, en la que, si bien en los preámbulos y en los artículos iniciales que establecen principios, parece vislumbrarse un cambio radical de postura ética, el desarrollo posterior del articulado del texto legal y de los reglamentos pertinentes acaban tirando por tierra cualquier pretensión de cambio. Tal es 
el caso, por ejemplo, de la Ley 51/2003, de Igualdad de oportunidades, no discriminación y accesibilidad universal, bastante buena en su preámbulo y articulado, pero cuyas disposiciones finales y reglamentos demoran o debilitan su plena aplicación, ya que permiten infringirla a muy bajo coste.

Creemos que aquellas teorías que dan voz y reconocen la dignidad de todos los actores implicados en la convivencia con el fenómeno de la diversidad funcional son más adecuadas que otras éticas, más anticuadas, que dan todo el protagonismo al sujeto aparentemente más capaz de la relación ética, facilitando el posible diseño de sociedades injustas que opriman a sus miembros más débiles.

La plasmación en leyes de los valores defendidos en una filosofía moral permite detectar rápidamente el grado de implantación de esos valores en el sistema legislativo y, por lo tanto, en la sociedad. Por ello, hemos analizado la presencia de estos valores en algunas de las leyes más importantes en el ámbito de la diversidad funcional, para rastrear la presencia de nuevas voces, que darían fundamento a la ley desde la nueva ética necesaria para la promoción de la autonomía y la interdependencia.

El modelo social y el de la diversidad se encuentran íntimamente relacionados con la incorporación de ciertos valores intrínsecos a los derechos humanos y aspiran a potenciar el respeto por la dignidad humana, la igualdad y la libertad personal, propiciando la inclusión social sobre la base de principios tales como la vida independiente, la no discriminación, la accesibilidad universal, la normalización de los entornos y el diálogo civil, entre otros (Romañach y Palacios, 2007).

Para conseguir este objetivo, el modelo social ofrece argumentos para promover nuevos marcos legislativos basados en sus ideas, como es el caso de la Convención Internacional sobre los Derechos de las Personas con Discapacidad de la ONU o leyes antidiscriminación específicas. Ambos tipos de leyes están ya relativamente extendidas en el mundo occidental (España con leyes como la Ley 51/2003, de Igualdad de oportunidades, no discriminación y accesibilidad universal. La Convención tiene sus raíces fundamentales en el modelo social ${ }^{10}$ y está en vigor en España desde el 3 de mayo de 2008, por lo que, la mayoría de los fundamentos éticos que en ella se establecen, disponen ahora de un apoyo legislativo en todo el Estado, al menos de manera formal. De hecho, con estas directrices podría descartarse ya, por obsoleta, discriminatoria e insuficiente, la Ley de Promoción de la Autonomía Personal

10. Para profundizar en las relaciones entre el modelo social y la Convención, véase Palacios (2008). 
y Atención a las personas en situación de dependencia, aprobada en España a finales del 2006. Esta Ley limita la libertad de las personas con diversidad funcional para participar y vivir de forma independiente incluidas en la comunidad (reconocido en el artículo 19 de la Convención), ya que ofrece una cartera de servicios que prioriza aquellos que fomentan su exclusión y aislamiento (como las residencias y la atención a domicilio) y ofrece de manera restrictiva aquellos servicios que mejor fomentan la autonomía (como la asistencia personal). ${ }^{11}$

La Convención promueve la revisión de toda normativa, esté o no dirigida a las personas con diversidad funcional, que pueda contener alguna vulneración de los derechos establecidos en ella. Por eso, con estos principios se cuestionan más de 120 leyes vigentes hoy en España (Romañach y RodriguezPicavea, 2009).

\section{Conclusiones}

A lo largo de este artículo se han analizado diferentes paradigmas morales, en busca de ideas que den fundamento a la nueva ética que precisa la nueva sociedad, en especial las nuevas situaciones de «inDependencia», y se han encontrado ideas relevantes, modelos y corrientes morales y éticas. Sin descartar las aportaciones de autores clásicos y modernos, Aristóteles, Hume, Kant, Rawls, etc., para el objetivo que nos incumbe, encontramos los principiales apoyos en voces contemporáneas como las de Jonas, MacIntyre, Sen o Nussbaum, que sientan las bases de la inevitable necesidad de afrontar este tema en el ámbito de la filosofía moral.

No obstante, para profundizar en los nuevos valores éticos, nos parecen más importantes las éticas que nacen de las voces nunca escuchadas y que hablan en primera persona: la ética del «cuidado» o de la «implicación», que surge de las voces feministas, aporta una manera más humana y menos abstracta de establecer valores. En ella aparece de manera natural la noción de interdependencia ya que establece que aquel por el que nos preocupamos depende del que se preocupa tanto como el que se ocupa depende de aquel por el que nos preocupamos.

Del modelo social se desprende la necesidad de desmedicalizar y desinstitucionalizar a las personas discriminadas por su diversidad funcional, y dotarlas de las herramientas necesarias para participar en la sociedad en igualdad de oportunidades con los demás. Para conseguir este objetivo, el modelo

11. Artículo 14.2 de la Ley 39/2006 de Promoción de la Autonomía Personal y Atención a las personas en situación de dependencia. 
social propone nuevas leyes, como es el caso de la Convención Internacional sobre los Derechos de las Personas con Discapacidad (diversidad funcional) de la ONU o leyes antidiscriminación específicas (como la Ley 51/2003 en España). El modelo de la diversidad va más allá del modelo social, y propone la aceptación de la diversidad funcional como parte de la enriquecedora diversidad humana y la consecución de la plena dignidad en la diversidad funcional. Para ello, establece dos ideas o valores fundamentales: dar el mismo valor a las vidas de todos los seres humanos y garantizar los mismos derechos y oportunidades a todas las personas. Con estas ideas se está en disposición de afrontar los retos planeadas por la sociedad moderna, entre otros la promoción de la autonomía de las personas en situaciones de discriminación y la erradicación de políticas asistenciales de dependencia. Las sociedades occidentales contemporáneas se ven ahora en una encrucijada en la que habrá que elegir entre una futura sociedad en libertad y dignidad en la diversidad, o el retorno paulatino y sutil a sociedades fracasadas, discriminatorias e injustas ya existentes en el pasado. El camino elegido dependerá de los valores éticos que se utilicen para recorrerlo.

Si imaginamos que la convivencia es un juego, lo primero que establecería una teoría ética clásica sería determinar qué competencias mínimas deben reunir los jugadores para poder participar en el juego. Si el jugador no cumple con el mínimo establecido por la teoría no podría participar plenamente, convirtiéndose en un sujeto pasivo del juego. Esto les ocurre a las personas con diversidad funcional, que se sienten discriminadas porque viven en una sociedad que ha sido diseñada sin tener en cuenta su voz. Desde el punto de vista de una ética de la interdependencia, no se trataría tanto de determinar quién puede jugar y quién no, sino más bien de determinar cómo deberían ser las reglas del juego para que cualquier jugador, fuera cual fuera su capacidad y modo de funcionar, pudiera participar en él. Es decir, se trataría de definir en qué consiste el «juego de la convivencia» siendo éste el único en el que todos podemos jugar, de lo contrario se trataría del «juego de la exclusión».

\section{Bibliografía}

ARISTóteles, Ética a Nicómaco, Madrid, Centro de Estudios Constitucionales, 1981.

- Retórica, Madrid, Instituto de Estudios Políticos, 1953.

ARNAU, S., «El "cuidado" y sus perversiones: la cultura de la violencia», en Revista Intersticios, vol. 3. n. ${ }^{\circ} 2$, 2009, [en línea] <http://www.intersticios.es/article/ view/4547/3176>. 
— «La "In-dependencia": Un nuevo Derecho de Ciudadanía. Una cuestión de Derechos Humanos», en XV Congrés Valencià de Filosofia, organizado por la Societat de Filosofia del País Valencià (Valencia, 6-8 de marzo de 2008), [en línea], <http://www.uv.es/sfpv/congressos_textos/congres17.pdf>.

BARNES, C., «Las teorías de la discapacidad y los orígenes de la opresión de las personas discapacitadas en la sociedad occidental», en Discapacidad y Sociedad, L. Barton (comp.), Madrid, Morata, S.L., 1998.

- «Disabled People in Britain and Discrimination. A case for Antidiscrimination Legislation», Hurst and Company, London in association with the British Council of Organizations of Disabled People, Third Edition, United Kingdom, 2000.

Barnes, C. y G. Mercer (eds.), Exploring the Divide: Illness and Disability, The Disability Press, Leeds, 1996.

Barnes, C., M. Oliver, y L. Barton (eds.), Disability Studies Today, Oxford, Polity Press, 2002.

BECCHI, P., «El itinerario filosófico de Hans Jonas. Etapas de un recorrido», en Isegoría, n. ${ }^{\circ}$ 39, Madrid, CSIC, 2008, pp. 101-128.

BONETE, E., Ética de la dependencia. Bases morales, debates políticos e implicaciones médicas de la Ley de Dependencia, Madrid, Tecnos, 2009.

Cejudo, R., «Capacidad y libertad. Una aproximación a la teoría de Amartya Sen», en Revista Internacional de Sociología, vol. LXV, n. ${ }^{\circ}$ 47, 2007.

García Alonso, J. V. (coord.), El movimiento de vida independiente. Experiencias Internacionales, Madrid, Fundación Luis Vives, 2003, [en línea], <http://www. asoc-ies.org/docs/mvi_exper_internac.pdf>.

HuME, D., Investigación sobre los principios de la moral, Madrid, Alianza, 1993.

- Tratado de la naturaleza humana, Madrid, Editora Nacional, 1981.

JONAS, H., El principio de la responsabilidad. Ensayo para una ética de la civilización tecnológica, Barcelona, Herder, 1995.

KANT, I., Fundamentación de la metafísica de las costumbres, Madrid, Tecnos, 2005.

- Metafisica de las costumbres, Madrid, Tecnos, 1989.

Macintyre, A., Animales racionales y dependientes, Barcelona, Paidós, 2001.

Maraña, J. J., Vida Independiente. Nuevos modelos organizativos, Santiago de Compostela, AIES, 2004, [en línea], <http://www.asoc-ies.org/docs/vinmo.pdf>.

- La experiencia de la independencia, Vedra, La Coruña, DIVERSITAS EdicionesAIES, España, 2007.

MARíN, G., «Ética de la justicia, ética del cuidado», 1993, [en línea], <http://www. nodo50.org/doneselx/assemblea/etica.htm>.

Noddings, N., Caring. A femenine Approach to Ethics \& Moral Education, University of California Press, 1984.

Nussbaum, M., Las fronteras de la justicia. Consideraciones sobre la exclusión, Barcelona, Ediciones Paidós Ibérica, 2007. 
Oliver, M., The politics of disablement, Londres, Macmillan, 1990.

ONU, «Convención sobre los Derechos de las Personas con Discapacidad y Protocolo Facultativo», 2007, [en línea], <http://www.un.org/disabilities/ documents/convention/convoptprot-s.pdf>.

Palacios, A., El modelo social de discapacidad: orígenes, caracterización y plasmación en la Convención Internacional sobre los Derechos de las Personas con Discapacidad, colección CERMI, n. ${ }^{\circ}$ 36, Madrid, Grupo editorial CINCA. octubre 2008.

RaWls, J., Teoría de la justicia, Madrid, Fondo de Cultura Económica, 1995.

ROMAÑACH, J. y M. LOBATO, «Diversidad funcional, nuevo término para la lucha por la dignidad en la diversidad del ser humano», 2005, [en línea], <http://www.minusval2000.com/relaciones/vidaIndependiente/diversidad_ funcional.html>.

ROMAÑACH, J. y PALACiOs, A. El modelo de la diversidad: La Bioética y los Derechos Humanos como herramientas para alcanzar la plena dignidad en la diversidad funcional, Valencia, Diversitas, 2006, [en línea], <http://www.asoc-ies.org/ docs/modelo\%20diversidad.pdf>.

- «El modelo de la diversidad: una nueva visión de la bioética desde la perspectiva de las personas con diversidad funcional (discapacidad)», II Encuentro Moral, Ciencia y Sociedad en la Europa del Siglo XXI: «Interdependencia: el bienestar como requisito de la dignidad», San Sebastián, 15 y 16 de marzo de 2007.

ROMAÑACH, J. y A. RODRíGUEZ-PiCAVEA, «El futuro de la autonomía personal. Análisis de la Ley de Promoción de la Autonomía y atención a las personas en situación de dependencia del Estado español bajo la perspectiva de la Convención internacional sobre los derechos de las personas con discapacidad (diversidad funcional)», 2009, [en línea], <http://www.diversocracia.org/ ideateca.htm>.

SEN, A., Commodities and capabilities, Ámsterdam, Elsevier Science, 1985.

- «Capability and Well-Being», en The Quality of Life, M. C. Nussbaum y A. Sen, (eds.), Oxford, Oxford University Press, 1993.

- Nuevo examen de la desigualdad, Madrid, Alianza, 1999.

SHAKESPEARE, T., «Disabled people's self-organisation: a new social movement?», Disability E Society, Vol. 8, n. ${ }^{\circ}$ 3, 1993, pp. 249-264.

— «Cultural Representations of Disabled People: Dustbins for Disavowal» in Disability \& Society No. 9, Vol. 3. 1994. pp. 283-301.

Sutherland, A. T., Disabled We Stand, Londres, Souvenir Press, 1981, [en línea], $<$ http://www.campusred.net/TELOS/articuloexperiencia.asp? idarticulo=1\&rev $=73>$.

TOBOSO, M. y S. ARNAU, «La discapacidad dentro del enfoque de capacidades y funcionamientos de Amartya Sen», en Araucaria. Revista Iberoamericana de 
Filosofía, Política y Humanidades, año 10, n. ${ }^{\circ}$ 20, segundo semestre de 2008, [en línea], <http://www.institucional.us.es/araucaria/nro20/ideas20_4.htm>. TOMÁs DE AQuino, Suma Teológica, Madrid, BAC, 2005.

ZOLA, I. K., "Toward the necessary universalizing of a disability policy», en The Milbank Quarterly, vol. 67, supp. 2, Pt. 2, 1989, 401-428. Reimpreso en The Milbank Quarterly, vol. 83, n. ${ }^{\circ} 4$, 2005, pp. 1-27.

\section{Nota:}

Este artículo se inscribe dentro del Proyecto «Filosofía de las tecnociencias sociales y humanas» (FFI2008-03599) del Plan Nacional de I+D+i (20082011) y del Proyecto Intramural del CSIC «Discapacidad, envejecimiento y calidad de vida». 